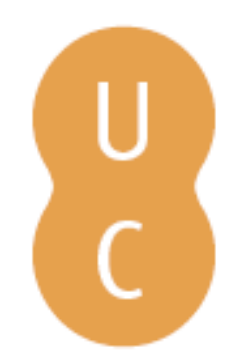

\title{
pombalina
}

\section{Reabilitação do centro histórico de V. N. de Gaia: um projeto de proteção civil}

Autor(es): $\quad$ Almeida, Salvador

Publicado por: Imprensa da Universidade de Coimbra; RISCOS - Associação

URL

persistente: URI:http://hdl.handle.net/10316.2/34943

DOI: $\quad$ DOI:http://dx.doi.org/10.14195/978-989-96253-3-4_143

Accessed : $\quad$ 26-Apr-2023 10:49:37

A navegação consulta e descarregamento dos títulos inseridos nas Bibliotecas Digitais UC Digitalis, UC Pombalina e UC Impactum, pressupõem a aceitação plena e sem reservas dos Termos e Condições de Uso destas Bibliotecas Digitais, disponíveis em https://digitalis.uc.pt/pt-pt/termos.

Conforme exposto nos referidos Termos e Condições de Uso, o descarregamento de títulos de acesso restrito requer uma licença válida de autorização devendo o utilizador aceder ao(s) documento(s) a partir de um endereço de IP da instituição detentora da supramencionada licença.

Ao utilizador é apenas permitido o descarregamento para uso pessoal, pelo que o emprego do(s) título(s) descarregado(s) para outro fim, designadamente comercial, carece de autorização do respetivo autor ou editor da obra.

Na medida em que todas as obras da UC Digitalis se encontram protegidas pelo Código do Direito de Autor e Direitos Conexos e demais legislação aplicável, toda a cópia, parcial ou total, deste documento, nos casos em que é legalmente admitida, deverá conter ou fazer-se acompanhar por este aviso.

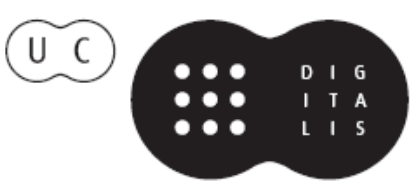



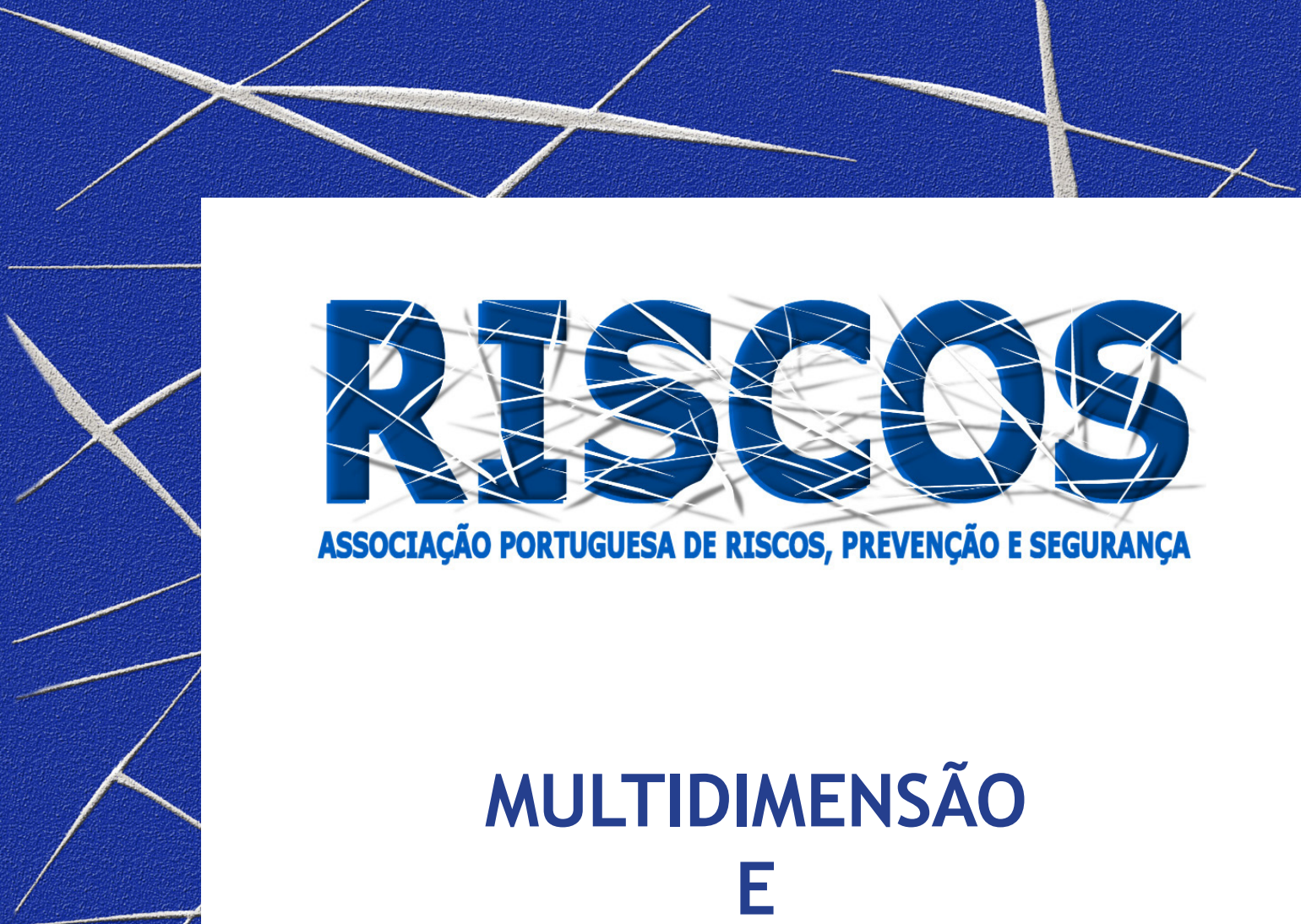

ASSOCIAÇÃO PORTUGUESA DE RISCOS, PREVENCCÃO E SEGURANÇA

MULTIDIMENSÃO

E
TERRITÓRIOS DE RISCO

III Congresso Internacional

I Simpósio Ibero-Americano

VIII Encontro Nacional de Riscos

Guimarães

2014 


\title{
REABILITAÇÃO DO CENTRO HISTÓRICO DE V. N. DE GAIA. UM PROJETO DE PROTEÇÃO CIVIL
}

\author{
Salvador Almeida \\ Comandante Bombeiros Sapadores e Proteção Civil de Vila Nova de Gaia \\ salvadorpfalmeida@gmail.com
}

\begin{abstract}
RESUMO
O Centro Histórico de V. N. de Gaia é um documento vivo das condições de vida e das técnicas de construção de gerações ancestrais representativo de valores culturais, por constituírem uma memória coletiva, não se podem perder por incúria ou desleixo.

É necessário chamar a atenção para as questões sanitárias, qualidade de vida, condições de habitabilidade, parques e zonas de lazer, turismo e segurança contra risco de incêndio, para promover uma prevenção e proteção mais eficazes na defesa do nosso Património Histórico e Cultural, numa conjugação da arquitetura e da engenharia tendo como base a organização social das suas gentes.

A resposta constitui o presente Projeto de Proteção Civil, com propostas de medidas preventivas, mitigadoras, com Planos de Prevenção e Atuação, salientando-se o Projeto Industrigaia, Plano 3P, Plano de Intervenção dos Bombeiros, Plano de Atuação em Cheias e Inundações, na certeza de que é uma tarefa de todos e para todos, sem esquecer as urgências ambientais.
\end{abstract}

Palavras-chave: Centro Histórico, Riscos, Prevenção, Planos e Reabilitação.

Introdução

O Centro Histórico de V. N. de Gaia objeto deste projeto é uma área com cerca de 152 ha e corresponde à Área Crítica de Recuperação e Reconversão Urbanística, conforme é definido no DR n. ${ }^{\circ}$ 54/97, de 19 de Dezembro, É uma área urbana a renascer que, face à excelente localização e elevados valores paisagísticos, se tornou um espaço de lazer e diversão qualificada, à qual se associam as Caves do Vinho do Porto (mais de 600 mil visitantes ano). Em 2006, foi apresentado um MasterPlan Cidade de Gaia - Estudo de Enquadramento Estratégico para a Revitalização do Centro Histórico de Vila Nova de Gaia. Está bem patente a vulnerabilidade dos habitantes do Centro Histórico e a amplificação social face às suas características sociais (pobreza e má qualidade da habitação) e o risco em que vivem (risco de incêndio e derrocadas) (Cutter et al, 2000).

Ao longo dos últimos 20 anos aconteceram muitos incêndios urbanos e industriais, cheias e inundações, deslizamentos, derrocadas, abatimentos e que me levam a afirmar que o Centro Histórico, uma área com fortes inclinações e os arruamentos íngremes e estreitos, apresentam elevados riscos hidrológicos, geomorfológicos, risco de incêndio pelo que podemos considerar este espaço como uma Bacia de Riscos (Rebelo, 2001a), pelo que o estudo geográfico das ocorrências mais graves impõe-se no sentido de procurar todas as causas e permitir à engenharia a busca de novas soluções (Rebelo, 1994). Como sugere (Cutter et all, 2000) os riscos interagem com processos culturais sociais e institucionais de tal modo sobre qualquer resposta pública o que nos ajuda a melhor interpretar as perceções do público e no fim de contas a ter as respostas dos políticos para o risco e perigo da sociedade.

0 trabalho que aqui se apresenta está organizado em três Capítulos.

No primeiro Capitulo caracteriza-se o Centro Histórico no contexto do Concelho de Vila Nova de Gaia, recorrendo à cartografia existente, definindo a sua localização, estudando o uso e 
ocupação do solo, o edificado, a rede viária, o seu parque habitacional, os aspetos geomorfológicos e geologia, o clima, a sua hidrografia e hidrogeologia, a análise socioeconómica.

No segundo Capitulo são tratados em pormenor os riscos mais importantes, nomeadamente riscos hidro-geomorfológicos e risco de incêndio.

\section{Riscos hidro-geomorfológicos analisou-se:}

As características do coberto vegetal, o estado do edificado, o estudo da permeabilidade atual do subsolo rochoso e o estudo dos declives;

Fez-se um levantamento das cheias ao longo dos últimos 250 anos, criou-se uma base de dados com todas as ocorrências (cheias e inundações) e elaborou-se uma Carta de Risco para previsão e mitigação das Cheias e Inundações;

Levantamento e análise das manifestações de instabilidade geomorfológica dos últimos 20 anos georreferenciadas num SIG. Elaborou-se uma Carta de Risco face a deslizamentos, derrocadas e outros acontecimentos - ocorrências em Infraestruturas e Vias de Comunicação.

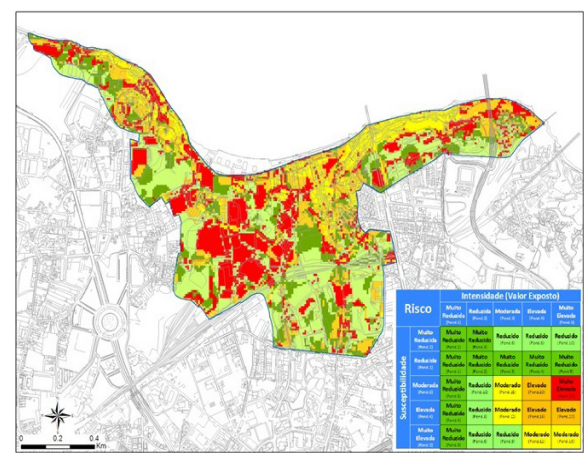

Figura 1 - Carta de Risco - Deslizamentos e Derrocadas em Infraestruturas e Vias de Comunicação

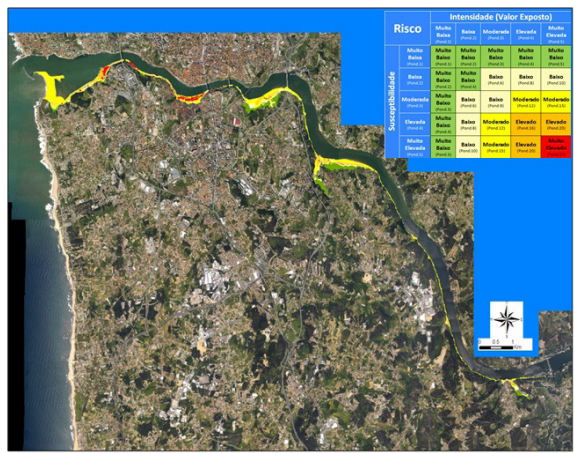

Figura 2 - Carta de Risco de Cheia da Orla Fluvial

\section{Risco de incêndio analisou-se:}

Levantamento e análise de vários incêndios devastadores da década de 70, 80 e 90 do século passado e a história dos incêndios dos últimos 20 anos georreferenciadas num SIG. Elaborou-se uma Carta de Risco de Incêndio e apresenta-se um conjunto de propostas para mitigar o risco, mas essencialmente, medidas de prevenção do risco e preparação do socorro.

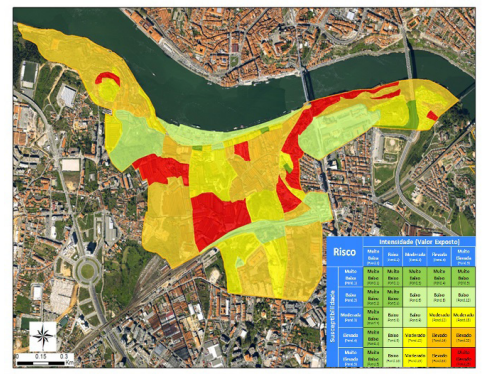

Figura 3 - Carta de Risco de Incêndio 
O terceiro capítulo é dedicado á elaboração de Planos de Emergência. A base de trabalho para minimizar o risco ou mesmo evitar o perigo deverá ser o Planeamento de Emergência e quanto menor for a dimensão da área da análise das vulnerabilidades, melhor será o resultado obtido (Alexandre, 2005).

Assim, partir do Planeamento Municipal $\left(167 \mathrm{Km}^{2}\right)$ para uma área micro $\left(1,52 \mathrm{Km}^{2}\right)$ e elaborar um Plano Especial de Emergência (alínea C- Artigo $3^{\circ}$, resolução $n^{\circ}$ 25/2008 de 18 Julho) que é um instrumento adequado e necessário ( $n^{\circ} 3$ - Artigo $2^{\circ}$, Resolução $n^{\circ} 25 / 2008$ de 18 Julho) é uma preocupação diária no âmbito das responsabilidades que exerço na proteção civil municipal (artigo $14^{\circ}$ - Lei n65/2007) e é uma obrigação:

- O Plano de Proteção Civil que é um Plano Especial, enquadrado pelo n. ${ }^{\circ} 2$ artigo $50^{\circ}$ da Lei n. ${ }^{\circ}$ 27/2006, de 3 de Julho, e na alínea c) do Artigo $3^{\circ}$ da Resolução n. ${ }^{\circ}$ 25/2008, de 18 de Julho.

- O Plano de Intervenção dos Bombeiros, destina-se aos Agentes de Proteção Civil, nomeadamente aos Corpos de Bombeiros de acordo com a alínea a) Artigo $46^{\circ}$ da Lei n. ${ }^{\circ}$ 27/2006, de 3 de Julho.

- O Plano de Intervenção na Salvaguarda do Património - Plano 3P que se destina aos Agentes de Proteção Civil, nomeadamente os Bombeiros (alínea a), Artigo $46^{\circ}$ da Lei n. ${ }^{\circ} 27$, de 3 de Julho) e aos gestores do património.

- O Plano Municipal de Prevenção e Atuação das cheias no Douro de V. N. de Gaia é um plano que se aplica à Orla Fluvial do Rio Douro dando ênfase ao Centro Histórico e representa um conjunto de normas e regras de procedimento.

- O Projeto Industrigaia é um projeto fundamental na defesa do Centro Histórico e de todo o concelho de Vila Nova de Gaia que permite aos Agentes de Proteção Civil (Bombeiros), ter informações ao minuto, via rádio quando se deslocam para a ocorrência, dos riscos existentes, das instalações, das fontes de energia, meios de proteção existentes, sistemas de extinção, abastecimento de água e riscos acrescidos.

\section{Conclusão}

\section{Riscos de Cheias e Inundações}

Como vamos mitigar os impactos materiais e sociais devido às cheias?

Com a correta ocupação do leito de cheia protegendo e conservando o mesmo, interditando a sua impermeabilização, cumprindo-se o D.L. 468/71 de 5 de Novembro, o D.L. 89/87 de 26 de Fevereiro, o D.L 166/2008 de 22 de Agosto e a Portaria 788/2009 de 28 de Julho e o Plano Municipal de Prevenção e Atuação de Cheias no Douro de V. N. Gaia, dando-se assim total cumprimento à diretiva europeia (European Commission, 2010), fazendo uma análise de risco baseada em dados quantitativos face aos impactos e extensão geográfica afetada.

Como medida fundamental para cumprirmos a sequência Prevenção - Preparação - Resposta

- Recuperação/Reabilitação, devemos realizar um exercício anual, em Outubro, pois sem dúvida que toda a orla fluvial do rio Douro e muito especial o Centro Histórico são lugares muito vulneráveis, mas nem sempre as populações os aceitam como tal, isto é, os lugares mais vulneráveis do ponto de vista geofísico não se integram sempre com as populações (Cutter et al, 2000) e, considerando que vulnerabilidade significa perda, a assunção que a vulnerabilidade é uma condição social, uma medida de resistência da sociedade ou resiliência a perigos (Blaickie et al, 1994), o cidadão comum tem tendência para esquecer os riscos de baixa probabilidade de ocorrência, mas com grandes impactos nas suas vidas. 


\section{Manifestações de instabilidade geomorfológica}

O trabalho apresentado evidencia que toda a orla fluvial de V. N. Gaia e principalmente no Centro Histórico a instabilidade geomorfológica é uma realidade e teve nos últimos anos impactos significativos sobre o ponto de vista económico, social e ambiental.

A Escarpa da Serra do Pilar é Reserva Ecológica Nacional pelo que todas as construções deverão ser demolidas cumprindo-se o estabelecido no D.L. 309/93 de 2 de Setembro.

\section{Risco de Incêndio}

Hoje como ontem a prevenção tem que ser o passo principal na preservação do Centro Histórico. Deverá ser promovida com toda a urgência a recuperação do edificado. Para diminuir os seus impactos no futuro é preciso reduzir a vulnerabilidade social e aumentar a resiliência aos incêndios com a melhoria das condições sociais e padrões de vida no Centro Histórico. Os incêndios são neutros e daltónicos, os seus impactos, no entanto, não são (Cutter, S., 2006). Elaborou-se o Plano de Intervenção dos Bombeiros, apoiado no Projeto Industrigaia e Plano 3P, para salvaguarda do património, definindo para as várias áreas e quarteirões, medidas simples de atuação para os Bombeiros.

Ao longo dos séculos, aconteceram cheias destruidoras ocasionadas pelo rio Douro. Há forte probabilidade de sofrer derrocadas provenientes das suas encostas, pois são áreas de muito alta susceptibilidade a movimentos de vertente. Tem uma probabilidade de risco de incêndio muito elevada, pelo que a implementação do Plano de Proteção Civil para o Centro Histórico, que coordena técnica e operacionalmente todos os agentes de proteção civil, englobando os riscos que enunciei é uma medida imperiosa, para enfrentar de forma consciente o aumento dos fenómenos que foram descritos, pois, por vezes, pessoas leigas têm falta de informação dos riscos.

Porém a sua conceptualização dos riscos é muito mais rica que a dos peritos e refletem preocupações que são tipicamente omissas na avaliação dos especialistas (Slovic, P, 1987).

O Centro Histórico de Vila Nova de Gaia merece o esforço de todos os agentes de proteção civil, pois o objetivo da gestão dos riscos e das crises é, sem dúvida, a redução das vulnerabilidades (Lourenço,L., 2003).

\section{Bibliografia}

ALEXANDER, David (2005); “Towards the development of a standard in emergency planning”. Disaster, Prevention and Management. 14(2) pp. 158-175.

BLAIKIE, Pier; CANNON, Terry; DAVIES, Ian; WISNER, Ben (1994); At Risk, Natural hazards, people 's vulnerability and disasters. Routledge, London, pp. 284, 23 figuras e 4 tabelas.

CUTTER, Susan L.; MITCHELL, Jerry T.; SCOTT, Michael S. (2000); "Revealing the vulnerability of people and places. A case study of Georgetown Country, South Carolina". Annals of the Association of American Geographers, 90(4), pp. 713-737.

CUTTER, Susan L. (2006); “The Geography of Social Vulnerability: Race, Class and Catastrophe”.)

European Commission, Commission Staff Working Papper (2010); “Risk assessment and mapping guidelines for disaster management”. Brussels.

LOURENÇO, Luciano (2003); "Análise de riscos e gestão de crises. O exemplo dos incêndios florestais". Territorium, (10), pp. 89-100.

MasterPlan Cidade de Gaia (2006); "Estudo de Enquadramento Estratégico para a revitalização do Centro Histórico de Vila Nova de Gaia". Parque Expo. 
CAPÍTULO 4: APLICAÇÃO DO PLANEAMENTO/PLANEJAMENTO E ORDENAMENTO DO TERRITÓRIO À GESTÃO DE RISCOS

REBELO, Fernando (2003); “Riscos Naturais e Acão Antrópica Estudos e Reflexões”. Coimbra, Imprensa da Universidade de Coimbra, 2 pp.286, $2^{a}$ edição revista.

SLOVIC, Paul (1987); “The preception of risk”. 236, pp. 280-285. 